\title{
Modeling and control of 41-level inverter using best switching angles calculation method
}

\author{
Alla Eddine Toubal Maamar, M'hamed Helaimi, Rachid Taleb, Abdelatif Gadoum \\ Electrical Engineering Department, Laboratoire Génie Electrique et Energies Renouvelables (LGEER), \\ Hassiba Benbouali University of Chlef, Algeria
}

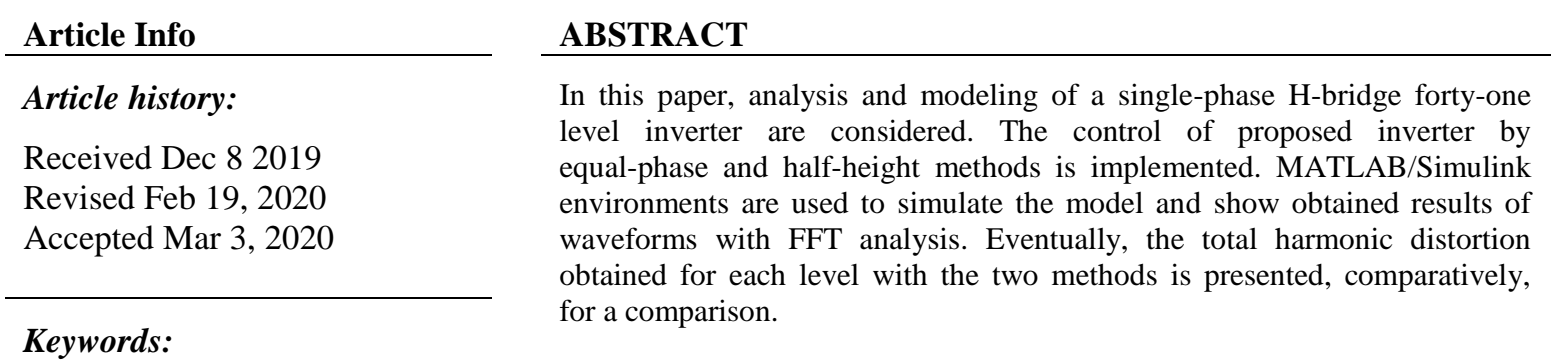

Equal-phase method Half-height method MATLAB/Simulink Multilevel inverter Power electronic

\section{Corresponding Author:}

Alla Eddine Toubal Maamar,

Electrical Engineering Department,

Laboratoire Génie Electrique et Energies Renouvelables (LGEER),

Hassiba Benbouali University of Chlef,

BP. 78C, Ouled Fares 02180, Chlef, Algeria.

Email: a.toubalmaamar@univ-chlef.dz

\section{INTRODUCTION}

Uses of cascaded H-bridge inverter have become more popular in power electronic applications because the simplicity of control and the ability to generate high output voltage levels $[1,2]$. Inverters can be classified into two types, voltage source inverter (VSI) and current source inverter (CSI). If the DC voltage is maintained and constant, the inverter is called VSI or voltage fed inverter (VFI), else if the input current is maintained and constant, the inverter is called CSI or current fed inverter (CFI) [3-6].

In applied power engineering fields, the multilevel inverter used in many applications [7-9], there are three conventional categories of the multilevel inverters: cascaded H-bridge, neutral point clamped and flying capacitor multilevel inverter [10-12]. The multilevel inverter used for Induction heating, Traction systems, Active filtering, Motor drives, High-voltage and Medium-voltage applications [13-14]. The problem is the choice of the switching angles required to control a multi-level inverter with a minimum THD in the system, total harmonic distortion is to the ratio between the RMS value of the signal harmonics (voltage or current) and the RMS value of the fundamental frequency [15].

To overcome the mentioned problem a modeling and simulation of a 41-level inverter using the best switching angles calculation method have been proposed using Simulink/MATLAB program, this solution for multilevel inverter control based on trigonometric calculation method. This paper is organized as follows, in Section II modeling and control of a multilevel inverter using Simulink/MATLAB have been discussed with an analysis of the two control methods, equal-phase (EP) method, half-height (HH) method. The results are presented and compared in Section III. Finally, some conclusions are presented in Section IV. 


\section{MODELING AND CONTROL OF MULTILEVEL INVERTER}

\subsection{The model of multilevel inverter}

The simulation model of a 41-level inverter is shown in Figure 1, consists of cascaded H-bridge inverters, DC power supplies and control block with adjusting the frequency and switching angles.

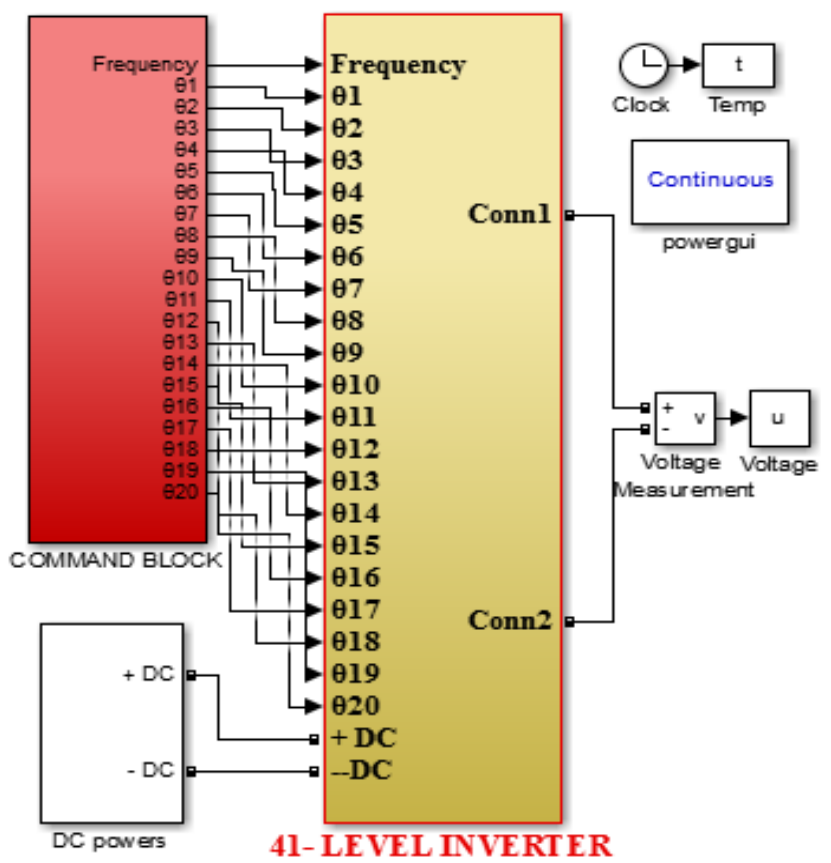

Figure 1. The MATLAB/Simulink model of 41-level inverter

\subsection{Control of inverter with equal-phase method}

Switching angles with the equal-phase (EP) method in degrees is shown in Table 1. The principle of this method is the division of the period $\left(180^{\circ}\right)$ by the inverter levels $(\mathrm{m})$ and multiplicative the result by the number of the angle (i) [5]. The formula of calculation is given by:

$$
\theta_{i}=\frac{180^{\circ}}{m} i, \quad i=1,2,3,4, \ldots, \frac{m-1}{2}
$$

Table 1. Switching angles with the EP method in degrees

\begin{tabular}{|c|c|}
\hline Level & Angles switching with the EP method in degrees \\
\hline 3 & $\theta 1=60$ \\
\hline 5 & $\theta 1=36 ; \theta 2=72$ \\
\hline 7 & $\theta 1=25.7143 ; \theta 2=51.4286 ; \theta 3=77.1429$ \\
\hline 9 & $\theta 1=20 ; \theta 2=40 ; \theta 3=60 ; \theta 4=80$ \\
\hline 11 & $\theta 1=16.3636 ; \theta 2=32.7273 ; \theta 3=49.0909 ; \theta 4=65.4545 ; \theta 5=81.8182$ \\
\hline 13 & $\theta 1=13.8462 ; \theta 2=27.6923 ; \theta 3=41.5385 ; \theta 4=55.3846 ; \theta 5=69.2308 ; \theta 6=83.0769$ \\
\hline 15 & $\theta 1=12 ; \theta 2=24 ; \theta 3=36 ; \theta 4=48 ; \theta 5=60 ; \theta 6=72 ; \theta 7=84$ \\
\hline 17 & $\theta 1=10.5882 ; \theta 2=21.1765 ; \theta 3=31.7647 ; \theta 4=42.3529 ; \theta 5=52.9412 ; \theta 6=63.5294 ; \theta 7=74.1176 ; \theta 8=84.7059$ \\
\hline 19 & $\theta 1=9.4737 ; \theta 2=18.9474 ; \theta 3=28.4211 ; \theta 4=37.8947 ; \theta 5=47.3684 ; \theta 6=56.8421 ; \theta 7=66.3158 ; \theta 8=75.7895 ; \theta 9=85.2632$ \\
\hline 21 & $\begin{array}{l}\theta 1=8.5714 ; \theta 2=17.1429 ; \theta 3=25.7143 ; \theta 4=34.2857 ; \theta 5=42.8571 ; \theta 6=51.4286 ; \theta 7=60.0000 ; \theta 8=68.5714 ; \theta 9=77.1429 ; \\
\theta 10=85.7143\end{array}$ \\
\hline 23 & $\begin{array}{l}\theta 1=7.8261 ; \theta 2=15.6522 ; \theta 3=23.4783 ; \theta 4=31.3043 ; \theta 5=39.1304 ; \theta 6=46.9565 ; \theta 7=54.7826 ; \theta 8=62.6087 ; \theta 9=70.4348 ; \\
\theta 10=78.2609 ; \theta 11=86.0870\end{array}$ \\
\hline 25 & $\begin{array}{l}\theta 1=7.2000 ; \theta 2=14.4000 ; \theta 3=21.6000 ; \theta 4=28.8000 ; \theta 5=36.0000 ; \theta 6=43.2000 ; \theta 7=50.4000 ; \theta 8=57.6000 ; \theta 9=64.8000 ; \\
\theta 10=72.0000 ; \theta 11=79.2000 ; \theta 12=86.4000\end{array}$ \\
\hline 27 & $\begin{array}{l}\theta 1=6.6667 ; \theta 2=13.3333 ; \theta 3=20.0000 ; \theta 4=26.6667 ; \theta 5=33.3333 ; \theta 6=40.0000 ; \theta 7=46.6667 ; \theta 8=53.3333 ; \theta 9=60.0000 ; \\
\theta 10=66.6667 ; \theta 11=73.3333 ; \theta 12=80.0000 ; \theta 13=86.6667\end{array}$ \\
\hline 29 & $\begin{array}{l}\theta 1=6.2069 ; \theta 2=12.4138 ; \theta 3=18.6207 ; \theta 4=24.8276 ; \theta 5=31.0345 ; \theta 6=37.2414 ; \theta 7=43.4483 ; \theta 8=49.6552 ; \theta 9=55.8621 ; \\
\theta 10=62.0690 ; \theta 11=68.2759 ; \theta 12=74.4828 ; \theta 13=80.6897 ; \theta 14=86.8966\end{array}$ \\
\hline 31 & $\begin{array}{l}\theta 1=5.8065 ; \theta 2=11.6129 ; \theta 3=17.4194 ; \theta 4=23.2258 ; \theta 5=29.0323 ; \theta 6=34.8387 ; \theta 7=40.6452 ; \theta 8=46.4516 ; \theta 9=52.2581 ; \\
\theta 10=58.0645 ; \theta 11=63.8710 ; \theta 12=69.6774 ; \theta 13=75.4839 ; \theta 14=81.2903 ; \theta 15=87.0968\end{array}$ \\
\hline
\end{tabular}


Table 1. Switching angles with the EP method in degrees (cont)

\begin{tabular}{cl}
\hline Level & Angles switching with the EP method in degrees \\
\hline 33 & $\theta 1=5.4545 ; \theta 2=10.9091 ; \theta 3=16.3636 ; \theta 4=21.8182 ; \theta 5=27.2727 ; \theta 6=32.7273 ; \theta 7=38.1818 ; \theta 8=43.6364 ; \theta 9=49.0909 ;$ \\
& $\theta 10=54.5455 ; \theta 11=60.0000 ; \theta 12=65.4545 ; \theta 13=70.9091 ; \theta 14=76.3636 ; \theta 15=81.8182 ;$ \\
& $\theta 16=87.2727$ \\
35 & $\theta 1=5.1429 ; \theta 2=10.2857 ; \theta 3=15.4286 ; \theta 4=20.5714 ; \theta 5=25.7143 ; \theta 6=30.8571 ; \theta 7=36.0000 ; \theta 8=41.1429 ; \theta 9=46.2857 ;$ \\
& $\theta 10=51.4286 ; \theta 11=56.5714 ; \theta 12=61.7143 ; \theta 13=66.8571 ; \theta 14=72.0000 ; \theta 15=77.1429 ;$ \\
& $\theta 16=82.2857 ; \theta 17=87.4286$ \\
& $\theta 1=4.8649 ; \theta 2=9.7297 ; \theta 3=14.5946 ; \theta 4=19.4595 ; \theta 5=24.3243 ; \theta 6=29.1892 ; \theta 7=34.0541 ; \theta 8=38.9189 ; \theta 9=43.7838 ;$ \\
& $\theta 10=48.6486 ; \theta 11=53.5135 ; \theta 12=58.3784 ; \theta 13=63.2432 ; \theta 14=68.1081 ; \theta 15=72.9730 ; \theta 16=77.8378 ; \theta 17=82.7027 ; \theta 18=$ \\
& 87.5676 \\
& $\theta 1=4.6154 ; \theta 2=9.2308 ; \theta 3=13.8462 ; \theta 4=18.4615 ; \theta 5=23.0769 ; \theta 6=27.6923 ; \theta 7=32.3077 ; \theta 8=36.9231 ; \theta 9=41.5385 ;$ \\
& $\theta 10=46.1538 ; \theta 11=50.7692 ; \theta 12=55.3846 ; \theta 13=60.0000 ; \theta 14=64.6154 ; \theta 15=69.2308 ;$ \\
& $\theta 16=73.8462 ; \theta 17=78.4615 ; \theta 18=83.0769 ; \theta 19=87.6923$ \\
& $\theta 1=4.3902 ; \theta 2=8.7805 ; \theta 3=13.1707 ; \theta 4=17.5610 ; \theta 5=21.9512 ; \theta 6=26.3415 ; \theta 7=30.7317 ; \theta 8=35.1220 ;$ \\
& $\theta 9=39.5122 ; \theta 10=43.9024 ; \theta 11=48.2927 ; \theta 12=52.6829 ; \theta 13=57.0732 ; \theta 14=61.4634 ; \theta 15=65.8537 ; \theta 16=70.2439 ;$
\end{tabular}

\subsection{Control of inverter with half-height method}

Switching angles with the half-height $(\mathrm{HH})$ is shown in Table 2. The Principe of the HH method [5] is presented by the following formula of calculation:

$$
\begin{aligned}
& \theta_{i}=\sin ^{-1}\left(\frac{2}{m-1}\left(i-\frac{1}{2}\right)\right)=\sin ^{-1}\left(\frac{2 i-1}{m-1}\right), \\
& \text { with } i=1,2,3,4, \ldots, \frac{m-1}{2}
\end{aligned}
$$

\begin{tabular}{|c|c|}
\hline Level & Angles switching with $\mathrm{HH}$ method in degrees \\
\hline 3 & $\theta 1=30$ \\
\hline 5 & $\theta 1=14.4775 ; \theta 2=48.5904$ \\
\hline 7 & $\theta 1=9.5941 ; \theta 2=30 ; \theta 3=56.4427$ \\
\hline 9 & $\theta 1=7.1808 ; \theta 2=22.0243 ; \theta 3=38.6822 ; \theta 4=61.0450$ \\
\hline 11 & $\theta 1=5.7392 ; \theta 2=17.4576 ; \theta 3=30 ; \theta 4=44.4270 ; \theta 5=64.1581$ \\
\hline 13 & $\theta 1=4.7802 ; \theta 2=14.4775 ; \theta 3=24.6243 ; \theta 4=35.6853 ; \theta 5=48.5904 ; \theta 6=66.4435$ \\
\hline 15 & $\theta 1=4.0960 ; \theta 2=12.3736 ; \theta 3=20.9248 ; \theta 4=30 ; \theta 5=40.0052 ; \theta 6=51.7868 ; \theta 7=68.2132$ \\
\hline 17 & $\theta 1=3.5833 ; \theta 2=10.8069 ; \theta 3=18.2100 ; \theta 4=25.9445 ; \theta 5=34.2289 ; \theta 6=43.4325 ; \theta 7=54.3409 ; \theta 8=69.6359$ \\
\hline 19 & $\begin{array}{l}\theta 1=3.1847 ; \theta 2=9.5941 ; \theta 3=16.1276 ; \theta 4=22.8854 ; \theta 5=30 ; \theta 6=37.6699 ; \theta 7=46.2383 ; \theta 8=56.4427 \\
\theta 9=70.8119\end{array}$ \\
\hline 21 & $\begin{array}{l}\theta 1=2.8660 ; \theta 2=8.6269 ; \theta 3=14.4775 ; \theta 4=20.4873 ; \theta 5=26.7437 ; \theta 6=33.3670 ; \theta 7=40.5416 ; \theta 8=48.5904 \\
\theta 9=58.2117 ; \theta 10=71.8051\end{array}$ \\
\hline 23 & $\begin{array}{l}\theta 1=2.6053 ; \theta 2=7.8375 ; \theta 3=13.1366 ; \theta 4=18.5530 ; \theta 5=24.1477 ; \theta 6=30.0000 ; \theta 7=36.2215 ; \theta 8=42.9859 \\
\theta 9=50.5994 ; \theta 10=59.7274 ; \theta 11=72.6586\end{array}$ \\
\hline 25 & $\begin{array}{l}\theta 1=2.3880 ; \theta 2=7.1808 ; \theta 3=12.0247 ; \theta 4=16.9578 ; \theta 5=22.0243 ; \theta 6=27.2796 ; \theta 7=32.7972 ; \theta 8=38.6822 \\
\theta 9=45.0995 ; \theta 10=52.3415 ; \theta 11=61.0450 ; \theta 12=73.4022\end{array}$ \\
\hline 27 & $\begin{array}{l}\theta 1=2.2042 ; \theta 2=6.6258 ; \theta 3=11.0875 ; \theta 4=15.6185 ; \theta 5=20.2522 ; \theta 6=25.0290 ; \theta 7=30.0000 ; \theta 8=35.2344 \\
\theta 9=40.8322 ; \theta 10=46.9509 ; \theta 11=53.8711 ; \theta 12=62.2042 ; \theta 13=74.0576\end{array}$ \\
\hline 29 & $\begin{array}{l}\theta 1=2.0467 ; \theta 2=6.1506 ; \theta 3=10.2866 ; \theta 4=14.4775 ; \theta 5=18.7493 ; \theta 6=23.1324 ; \theta 7=27.6640 ; \theta 8=32.3924 ; \\
\theta 9=37.3832 ; \theta 10=42.7321 ; \theta 11=48.5904 ; \theta 12=55.2281 ; \theta 13=63.2345 ; \theta 14=74.6411\end{array}$ \\
\hline 31 & $\begin{array}{l}\theta 1=1.9102 ; \theta 2=5.7392 ; \theta 3=9.5941 ; \theta 4=13.4934 ; \theta 5=17.4576 ; \theta 6=21.5102 ; \theta 7=25.6793 ; \theta 8=30.0000 ; \theta 9=34.5181 ; \theta 10= \\
39.2965 ; \theta 11=44.4270 ; \theta 12=50.0555 ; \theta 13=56.4427 ; \theta 14=64.1581 ; \theta 15=75.1649\end{array}$ \\
\hline 33 & $\begin{array}{l}\theta 1=1.7908 ; \theta 2=5.3794 ; \theta 3=8.9893 ; \theta 4=12.6356 ; \theta 5=16.3348 ; \theta 6=20.1055 ; \theta 7=23.9695 ; \theta 8=27.9532 ; \theta 9=32.0900 ; \theta 10= \\
36.4236 ; \theta 11=41.0145 ; \theta 12=45.9514 ; \theta 13=51.3752 ; \theta 14=57.5383 ; \theta 15=64.9922 ; \theta 16=75.6385\end{array}$ \\
\hline 35 & $\begin{array}{l}\theta 1=1.6854 ; \theta 2=5.0621 ; \theta 3=8.4565 ; \theta 4=11.8812 ; \theta 5=15.3495 ; \theta 6=18.8765 ; \theta 7=22.4795 ; \theta 8=26.1790 ; \theta 9=30.0000 ; \theta 10= \\
33.9745 ; \theta 11=38.1445 ; \theta 12=42.5685 ; \theta 13=47.3321 ; \theta 14=52.5720 ; \theta 15=58.5330 ; \theta 16=65.7504 ; \theta 17=76.0694 \\
\theta 1=1.5918 ; \theta 2=4.7802 ; \theta 3=7.9836 ; \theta 4=11.2123 ; \theta 5=14.4775 ; \theta 6=17.7916 ; \theta 7=21.1684 ; \theta 8=24.6243 ; \theta 9=28.1786 ; \theta 10=\end{array}$ \\
\hline 37 & $\begin{array}{l}31.8554 ; \theta 11=35.6853 ; \theta 12=39.7090 ; \theta 13=43.9830 ; \theta 14=48.5904 ; \theta 15=53.6639 ; \\
\theta 16=59.4416 ; \theta 17=66.4435 ; \theta 18=76.4638 \\
\theta 1=15080 \cdot \theta 2=45281 \cdot \theta 3=75608 \cdot \theta 4=106151 \cdot \theta 5=137002 \cdot \theta 6=168264 \cdot \theta 7=200052 \cdot \theta 8=232496 \cdot \theta 9=26.5750 \cdot \theta 10=\end{array}$ \\
\hline 39 & $\begin{array}{l}\theta 1=1.5080 ; \theta 2=4.5281 ; \theta 3=7.5608 ; \theta 4=10.6151 ; \theta 5=13.7002 ; \theta 6=16.8264 ; \theta 7=20.0052 ; \theta 8=23.2496 ; \theta 9=26.5750 ; \theta 10= \\
30.0000 ; \theta 11=33.5477 ; \theta 12=37.2478 ; \theta 13=41.1395 ; \theta 14=45.2778 ; \theta 15=49.7434 ; \\
\theta 16=54.6655 ; \theta 17=60.2757 ; \theta 18=67.0805 ; \theta 19=76.8264\end{array}$ \\
\hline 41 & $\begin{array}{l}\theta 1=1.4325 ; \theta 2=4.3012 ; \theta 3=7.1808 ; \theta 4=10.0787 ; \theta 5=13.0029 ; \theta 6=15.9620 ; \theta 7=18.9656 ; \theta 8=22.0243 ; \theta 9=25.1507 ; \\
\theta 10=28.3594 ; \theta 11=31.6682 ; \theta 12=35.0996 ; \theta 13=38.6822 ; \theta 14=42.4542 ; \theta 15=46.4688 ; \theta 16=50.8050 ; \theta 17=55.5885 ; \\
\theta 18=61.0450 ; \theta 19=67.6684 ; \theta 20=77.1614 .\end{array}$ \\
\hline
\end{tabular}

Table 2. Switching angles with the HH method in degrees 


\section{RESULTS AND DISCUSSION}

Some obtained results are presented in this session with a comparison. Figure 2 show the output voltage waveform and Figure 3 show the harmonic spectrum of a 41-level inverter with EP method. Figure 4 show the 41-level inverter output waveform with $\mathrm{HH}$ method and Figure 5 show the harmonic spectrum analysis with $\mathrm{HH}$ method of a 41-level inverter. Table 3 shows the data comparison and Figure 6 show a graphic comparison of THDs between the EP method and HH method.

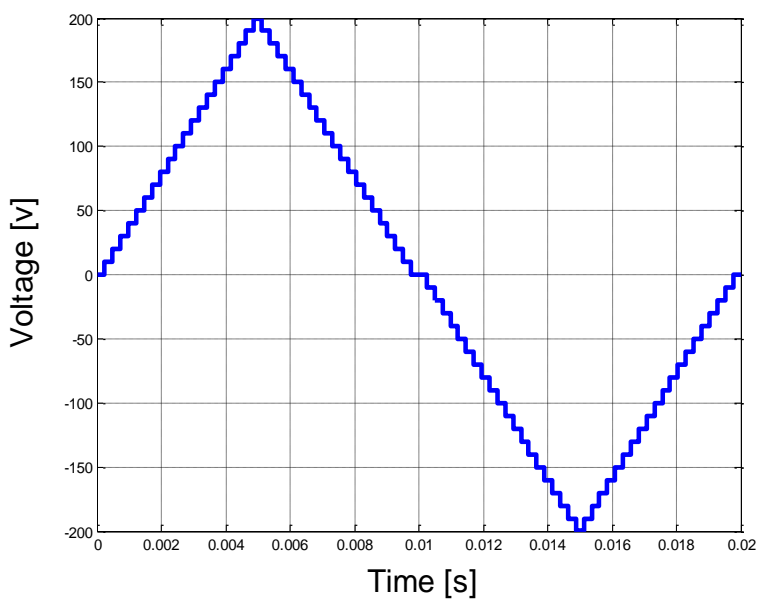

Figure 2. The output voltage waveform of a 41-level inverter with EP method

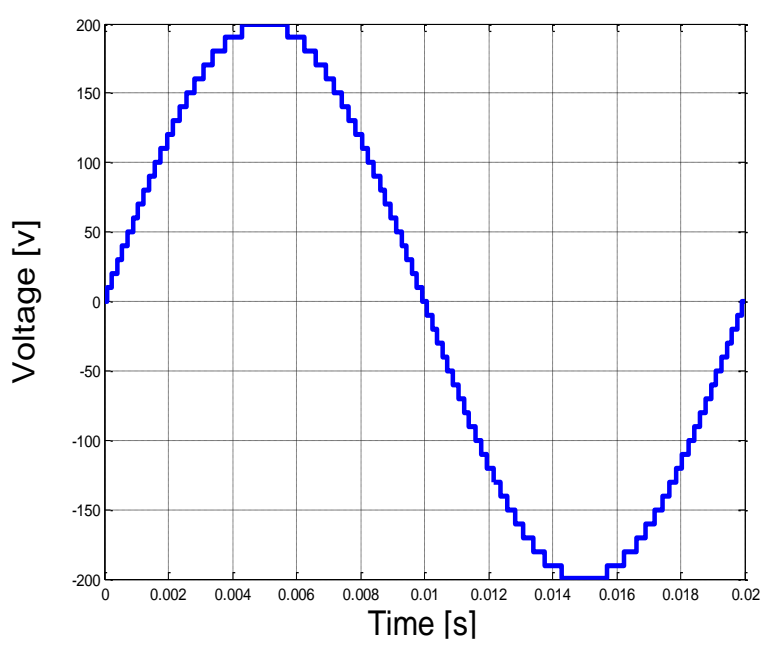

Figure 4. Output voltage waveform for a 41-level inverter with the $\mathrm{HH}$ method

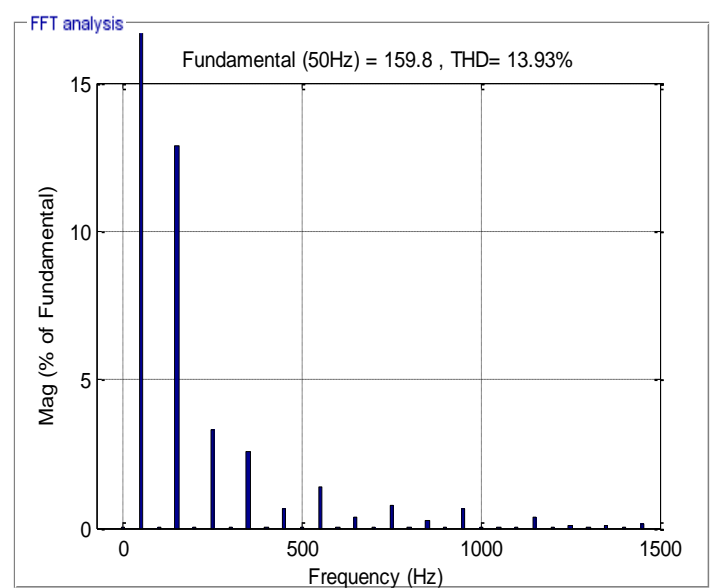

Figure 3. THD Analysis of 41-Level output voltage with the EP method

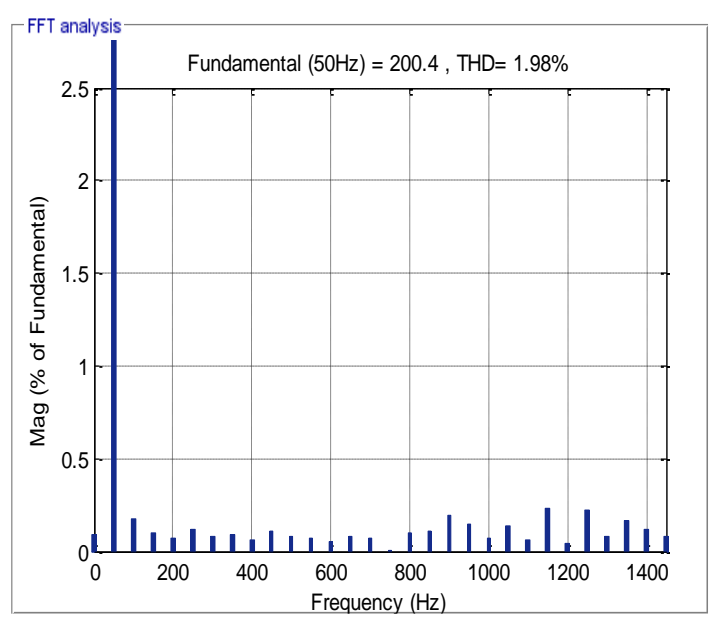

Figure 5. THD analysis of 41-level output voltage with the $\mathrm{HH}$ method

The Figure 2 and Figure 4 are the output voltage waveforms of the 41 -level inverter with the two control methods, EP method and HH method, and the Figure 3 and Figure 5 are the total harmonic distortion THD of the 41-level inverter with the two methods respectively. From the analysis of THD comparison between the two control methods in Figure 6, we can say that there is a decrease of THD with an increase of inverter level, and for each inverter level, the THD with EP control method is higher than that obtained with $\mathrm{HH}$ control method. THD of the 17-level inverter with $\mathrm{HH}$ control method is down of $5 \%$, and with EP method is $18.15 \%$. THD of a 41 -level inverter with HH control method is $1.98 \%$, and with EP method is 13.93\%. We note that the harmonic voltage is limited by the standard IEEE STD 519 [16]: The total harmonic distortion of voltage $\mathrm{THDv}<5 \%$, and conclude that the $\mathrm{HH}$ method gives a good result with 17-level cascaded H-bridge inverter. 
Table 3. THD with two methods, comparisons

\begin{tabular}{ccc}
\hline Level & THD (\%) with EP method & THD $(\%)$ with HH method \\
\hline 3 & 78.55 & 31.87 \\
5 & 38.96 & 17.53 \\
7 & 30.02 & 12.09 \\
9 & 25.82 & 9.28 \\
11 & 21.75 & 7.48 \\
13 & 20.24 & 6.35 \\
15 & 18.75 & 5.47 \\
17 & 18.15 & 4.82 \\
19 & 17.27 & 4.32 \\
21 & 16.49 & 3.89 \\
23 & 15.94 & 3.55 \\
25 & 15.86 & 3.24 \\
27 & 15.16 & 3.05 \\
29 & 14.05 & 2.80 \\
31 & 14.74 & 2.65 \\
33 & 14.45 & 2.47 \\
35 & 14.19 & 2.36 \\
37 & 14.07 & 2.21 \\
39 & 14.14 & 2.10 \\
41 & 13.93 & 1.98 \\
\hline
\end{tabular}

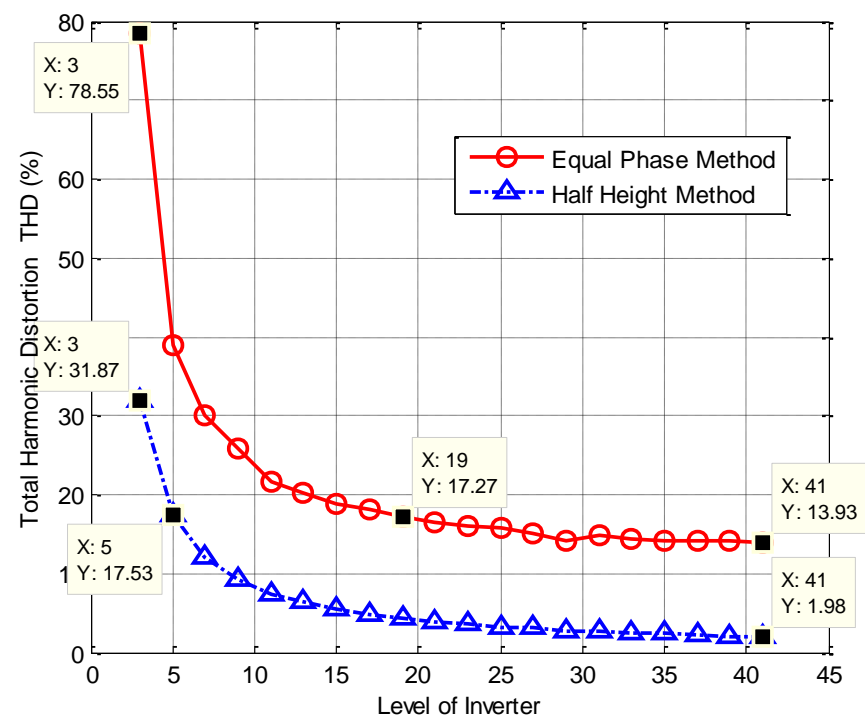

Figure 6. THD comparison at different levels with the two control methods

\section{CONCLUSION}

In this paper, contribution to the modeling and control of 41-level inverter using best switching angles calculation method is presented with two control methods. From simulation and THD compared results it has been observed that $\mathrm{HH}$ method is the best method for switching angles than the EP method.

\section{REFERENCES}

[1] H. Akagi, "Multilevel Converters: Fundamental Circuits and Systems," in Proceedings of the IEEE, vol. 105, no. 11, pp. 2048-2065, Nov. 2017.

[2] Yaosuo Xue, Liuchen Chang, Sren Baekhj Kjaer, J. Bordonau, and T. Shimizu, "Topologies of single-phase inverters for small distributed power generators: an overview," in IEEE Transactions on Power Electronics, vol. 19, no. 5, pp. 1305-1314, Sept. 2004.

[3] Bolla Madhusudana Reddy, Y. V. Siva Reddy, and M. Vijaya Kumar, "Modeling and Simulation of 127 Level Optimal Multilevel Inverter with Lower Number of Switches and Minimum THD," International Journal of Power Electronics and Drive System, vol. 9, no. 4, pp. 1765-1773, 2018.

[4] K. Dhineshkumar, C. Subramani, A. Geetha, and C. Vimala, "Performance analysis of PV powered multilevel inverter," International Journal of Electrical and Computer Engineering, vol. 9, no. 2, pp. 753-760, 2019.

[5] F.L. Luo and H. Ye, "Advanced DC/AC inverters application in renewable energy," CRC Press Taylor \& Francis Group, 2013. 
[6] Q.-C. Zhong and T. Hornik, "Control of power inverters in renewable energy and smart grid integration," New York, NY, USA: Wiley, 2013

[7] Jagabar Sathik Mohd.Ali and Vijayakumar Krishnaswamy, "An assessment of recent multilevel inverter topologies with reduced power electronics components for renewable applications," Renewable and Sustainable Energy Reviews, vol. 82, part 3, pp. 3379-3399, 2018

[8] C. R. Balamurugan and R. Besnraj, "Analysis of various carriers overlapping PWM strategies for a single phase ternary multilevel inverter," International Journal of Applied Power Engineering, vol.7, no.1, pp. 27-39, 2018.

[9] S. Chikkam and B. Ranganaik, "Modeling and simulation of a novel three-phase multilevel inverter with induction motor drive," International Journal of Research in Advent Technology, vol. 2, no. 11, pp. 40-44, 2014.

[10] M. Aravindan, V. Balaji, V. Saravanan and M. Arumugam, "Neutral point clamped quasi Z source inverter for photovoltaic systems," International Journal of Applied Power Engineering, vol. 8, no. 3, pp. 277-286, 2019.

[11] R. Taleb, D. Benyoucef, M. Helaimi, Z. Boudjemaa, and H. Saidi, "Cascaded H-bridge asymmetrical seven-level inverter using THIPWM for high power induction motor," Energy Procedia, vol. 74, pp. 844-853, 2015.

[12] M. Ahmed, M. Orabi, S. Ghoneim, M. Alharthi, F. Salem, B. Alamri, and S. Mekhilef, "Selective harmonic elimination method for unequal DC sources of multilevel inverters," Automatika, vol. 60, no. 4, pp. 378- 384, 2019.

[13] A. E. Toubal Maamar, M. Helaimi, R. Taleb, and F. Chabni, "Analysis and implementation of half-bridge series resonant inverter using Arduino," ICCEE'18 International Conference on Communications and Electrical Engineering El-Oued, Algeria, 2018.

[14] M. Vijeh, M. Rezanejad, E. Samadaei, and K. Bertilsson, "A general review of multilevel inverters based on main submodules: structural point of view," in IEEE Transactions on Power Electronics, vol. 34, no. 10, pp. 9479-9502, Oct. 2019.

[15] A. E. Toubal Maamar, M. Helaimi, R. Taleb, H. Mouloudj, O. Elamri, and A. Gadoum, "Mathematical analysis of N-R algorithm for experimental implementation of SHEPWM control on single-phase inverter," International Journal of Engineering Trends and Technology, vol. 68, no. 2, pp. 9-16, 2020.

[16] S. S. Rangarajan, E. R. Collins, and J. C. Fox, "Detuning of harmonic resonant modes in accordance with IEEE 519 standard in an exemplary north american distribution system with PV and wind," 2017 IEEE 6th International Conference on Renewable Energy Research and Applications (ICRERA), San Diego, CA, 2017, pp. 435-440.

\section{BIOGRAPHIES OF AUTHORS}

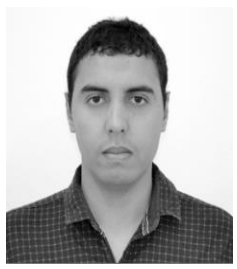

Alla Eddine Toubal Maamar received the B. Eng. degree and master degree in electrical engineering from University of Akli Mohand Oulhadj Bouira (UAMOB), Algeria, in 2014 and 2016, respectively. He is currently with the Department of Electrical Engineering and (LGEER) Laboratory, Hassiba Benbouali University of Chlef, Algeria. His research interests include the design, analysis and control of power electronic converters, electric machine control, multilevel inverters, artificial neural network (ANNs), robotics technology, renewable energy technologies.

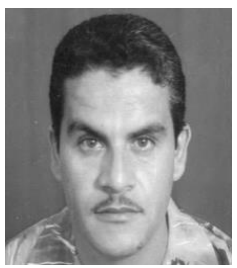

M'hamed Helaimi received the engineering degree in 2001, and magister degree in electrical engineering in 2004 from Hassiba Benbouali University, Chlef (UHBC), Algeria, and received the Ph.D. degree in electrical engineering from the University of Sciences and Technology of Oran (USTO), Bir El Djir, Algeria, in 2014. He joined the Department of Electrical Engineering, Chlef University, in 2004. His scientific work is related to dynamic modeling and control of nonlinear systems, genetic algorithms and artificial intelligence, induction heating applications and power electronics.

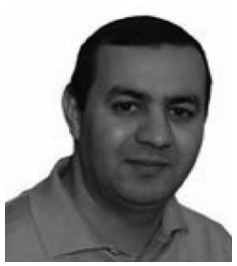

Rachid Taleb received the M.S. degree in electrical engineering in 2004, from Hassiba Benbouali University, and the Ph.D. degree in electrical engineering in 2011, from Djillali Liabes University, Algeria. He is currently an associate professor in the Department of Electrical Engineering, Hassiba Benbouali University, chlef, Algeria. He is also team leader of the Laboratoire Génie Electrique et Energies Renouvelables (LGEER) Laboratory. His research interests include power electronics, artificial intelligence control, heuristic optimization algorithms, and control theory of converters for renewable energy sources.

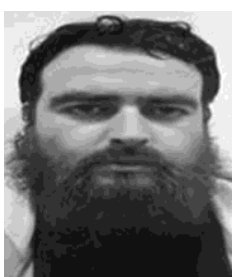

Abdelatif Gadoum was born in Bejaia, Algeria, in 1988. Received the Ph.D. degree in electrical engineering in 2019, from Hassiba Benbouali University of Chlef, Chlef, Algeria. His current research interests include gas discharges and modeling of low-pressure discharge and their applications. 